\title{
MULHERES NEGRAS, REMOÇÃO E ALINHAMENTOS DISCURSIVO: A VIDA NO BAIRRO CARIOCA DE TRIAGEM
}

- JÉSSICA MARA RAUL'

Resumo: Este artigo integra uma investigaçãa mais ampla que parte do questionamento sobre os efeitas das transformaçães acorridas na cidade do Rio de Janeiro enfrentadas pelas famílias chefiadas por mulheres negras moradoras do bairro carioca de Triagem por consequência de sua remação do Morro do Turano, procurando caracterizar suas estratégias de enfrentamento no decorrer desse pracesso. A partir do pensamento de que as remaçães contribuem рага ргесагizar as condiçães de sobrevivência das famílias faveladas, com maior ргеjuízo para as famílias chefiadas por mulheres negras, tendo como parâmetro sua desvantagem histórica proporcionada pela interseccionalidade de opressões de raça, gênero e classe, que coloca as mulheres negras em desvantagem histórica na busca pela efetivação da cidadania. Assim, a partir das falas das/os sujeitas/os, verificamos camo estes se organizam para o enfrentamento dessa realidade, com o objetivo de observar como as práticas saciais se evidenciam nos discursos.

Palavras-chave: mulheres negras, Remaçãa, cidadania pelo consuma, Bairro Cariaca de Triagem.

\section{Introdução}

Este artigo busca verificar como as famílias negras enfrentaram os impactos da remoção do Morro do Turano para o
Bairro carioca de Triagem, partindo da hipótese de que tal processo contribui para precarizar as condições de sobrevivência das famílias chefiadas por essas mulheres, na medida em que as obrigam a romper 
com laços de solidariedade dentro de suas localidades de origem. A descrição do Bairro carioca de Triagem nos remete ao universo encontrado pelas/os nossas/os sujeitas/os.

Para tanto, parte da compreensão de que a cidade do Rio de Janeiro passa, a partir da década de $1990^{2}$, por profundas transformações se tornando um produto no mercado mundial de cidades, que então orientada o planejamento urbano e as políticas habitacionais, assumindo um status de cidade-mercadoria. Além disso, a cidade já tem como marca de suas políticas urbanas, reformas que acabam por remover $^{3}$ as classes populares das áreas valorizadas para o mercado imobiliário e, nesse sentido, a fase atual do desenvolvimento capitalista - que tem a cidade como um de seus produtos impulsiona as políticas públicas, tornandoas competitivas e com um padrão de urbanização voltado a atender a esse mercado.

Fernanda Sáchez (2001) e o conceito de Cidade-mercadoria pensado por ela, nos possibilita pensar os processos pelos quais atravessa a cidade do Rio de Janeiro. A autora, indica a existência de um mercado mundial de cidades, junto a uma estratégia comum de políticas urbanas, voltada para a venda de cidades. Para a autora, essa transformação das cidades em mercadorias vem indicar que o processo de mercantilização do espaço atinge um novo patamar em que a existência de um mercado de cidades mostra a importância cada vez maior do espaço no capitalismo: a orientação estratégica para a conquista do espaço, que agora alcançaria cidades como um todo, postas em circulação num mercado mundial, evidencia a produção global do espaço social (SÁNCHEZ, 2001, p. 246).

Nessa perspectiva, as favelas se tornariam o ponto fraco da cidade necessitando de políticas específicas e por isso o Morro do Turano, situado na Zona Norte da cidade, passa atualmente por dois processos simultâneos característicos da nova política urbana para as favelas: o processo de parcial remoção - com a justificativa ambiental - e a militarização, que ocorre a partir da ocupação do território, realizado pela Unidade de Polícia Pacificadora e que compõe o projeto de cidade-negócio como viabilizador da valorização de áreas degradadas pela atuação do tráfico de drogas.

\section{O Programa Morar Carioca}

As reflexões desta seção buscam compreender o que foi considerado "o maior programa de urbanização de favelas 
do país", o Programa de Integração de Assentamentos Precários Informais Morar Carioca ${ }^{4}$ na tessitura do Rio de Janeiro enquanto uma cidade competitiva. Para Ferreira (2013), é nas favelas como o "lugar das ilegalidades" que a pobreza e a miséria possuem disposição geográfica específica e desde a década de 1940 esses espaços passam por intervenção de políticas públicas. Segundo a autora, tivemos a criação de alguns conjuntos habitacionais, parques proletários e obras de urbanização (Ferreira, 2013: 5).

O Morar Carioca tem como referência o programa Favela Bairro (1994 a 2009) e tinha a proposta de ampliar a acessibilidade com a construção de vias e planos inclinados, criando conjuntos de apartamentos que permitiriam a liberação de espaços de recreação e lazer e prevendo também ações como coleta seletiva, captação de água de chuva. Lançado em julho de 2010 como um novo plano para as favelas do município, o programa é parte do Plano Municipal de Habitação de Interesse Social, para urbanização, regularização e provisão de moradias ${ }^{6}$, com o objetivo oficial promover a inclusão através da integração urbana e social completa e definitiva de todas as favelas do Rio até o ano de 2020.

A meta era investir $\mathrm{R} \$ 8,5$ bilhões até 2020, financiados pelo governo federal e Banco Interamericano de Desenvolvimento (BID) ${ }^{7}$. Em outubro de 2012 foi assinado um convênio com o Instituto de Arquitetos do Brasil (IABRJ), para realização do Concurso Morar Carioca: conceituação e prática em urbanização de favelas. A iniciativa selecionou 40 escritórios de arquitetura que iriam desenvolver projetos de urbanização de comunidades, respeitando a cultura e a história dos seus moradores.

Segundo o site da Prefeitura do Rio $^{6}$, as obras de urbanização do Morar Carioca são executadas de acordo com o porte e a condição de cada comunidade, nas enquadradas como urbanizáveis e Áreas de Especial Interesse Social, portanto, as áreas de risco estavam previstas para serem eliminadas ${ }^{8}$.

Alexandre Magalhaes (2013), ressalta que embora o Morar Carioca seja apresentado como um dos "legados" dos Jogos Olímpicos, sua formulação já aparecia no início do atual governo que, em 2009, informa a realização de contatos com o BID para obter recursos para o chamado de "Favela-Bairro 3", dando continuidade às intervenções em curso há mais de uma década, mas lançado em um contexto específico marcado pelo debate em torno das consequências das "chuvas de abril" e no âmbito da preparação da cidade para a realização das Olimpíadas, se 
transformando, a partir da escolha da cidade do Rio de Janeiro como sede desse megaevento, no "legado" da realização dos Jogos, e compondo um dos compromissos que a "cidade" havia estabelecido com o Comitê Olímpico Internacional quando de sua candidatura (MAGALHÃES, 2013: $110)$.

Ao discutir uma das dimensões da "reatualização das práticas e discursos sobre a remoção de favelas no Rio de Janeiro", o autor demonstra que através da justificativa do "legado" estaria em curso uma transformação no enquadramento do "problema favela", tendo como característica fundamental a reincorporação da remoção no campo das intervenções possíveis do Estado nessas localidades. Para ele, as intervenções urbanísticas em curso vêm implicando alterações significativas nos fluxos e usos do espaço da cidade provocando o deslocamento de moradores de algumas favelas. Esse processo tem sido traduzido pelas autoridades públicas envolvidas, bem como em relação a outras intervenções, como um "legado" permitido pela concretização desses megaeventos e representando uma inflexão importante na conformação do "problema favela" na atual conjuntura (MAGALHÃES, 2013: 110).
O programa incorpora as ações de erradicação em curso desde o início de 2010, justificadas pela tragédia provocada das "chuvas de abril" e aumentaria consideravelmente em relação ao que fora o Favela-Bairro, tanto no que se refere à quantidade de favelas como no tipo de intervenção, incorporando "desadensamento", pela via do "reassentamento de áreas de risco", ou através da abertura de grandes vias de acesso e obras como teleféricos e planos inclinados (Idem: 111-112).

Magalhães completa dizendo que o programa poderia ser compreendido como expressão de uma das dimensões da transformação na maneira de enquadrar moralmente as favelas que vem se configurando, já que, a partir da análise do que fora interpretado como "deficiências" do Favela-Bairro ${ }^{8}$. Para ele, a partir da explicitação do que dizem e realizam os diversos atores, ao fazerem emergir $o$ termo "remoção" no debate sobre as favelas, seria possível entrever a realização de um duplo movimento de remoção e urbanização, a partir de parâmetros que se justifica com o argumento de "legado", elemento indissociável, segundo essa lógica, da realização dos megaeventos esportivos (Ibidem: 115).

Portanto, a partir do enquadramento do Bairro Carioca 
enquanto um legado dos Jogos Olímpicos foi possível justificar remoções na cidade, autorizadas como um benefício para os moradores realocados no espaço urbano. Nesse sentido, se torna necessário verificar o ponto de vista dessas pessoas no que tange a essas mudanças. A partir de suas falas resgatamos algumas percepções transmitidas pelos indivíduos, com o objetivo de observar como as práticas das/os nossas/os sujeitas/os se revelam nos discursos, além de demonstrar suas principais estratégias de sobrevivência.

\section{A interseccionalidade na vida das mulheres do Bairro Carioca de Triagem}

Através do depoimento das pessoas removidas do Morro do Turano, buscouse identificar os efeitos das transformações ocorridas na cidade do Rio de Janeiro enfrentadas pelas famílias chefiadas por mulheres negras moradoras do Bairro Carioca de triagem por consequência de sua remoção do Morro do Turano, partindo da ideia de que a interseccionalidade das opressões de raça, gênero e classe coloca estas mulheres em desvantagem social na busca por direitos, inclusive à moradia adequada, um dos direitos sociais tidos como fundamentais.
Segundo Crenshaw (2002), a interseccionalidade é uma conceituação do problema que busca capturar as consequências estruturais e dinâmicas da interação entre dois ou mais eixos da subordinação. Ela trata especificamente da forma pela qual o racismo, o patriarcalismo, a opressão de classe e outros sistemas discriminatórios criam desigualdades básicas que estruturam as posições relativas de mulheres, raças, etnias, classes e outras (CRENSHAW, 2002, p. 177).

A necessidade de entender quem são essas mulheres surge a partir da constatação de que suas condições de vida antes da remoção, terá impacto direto em sua avaliação sobre suas condições de vida.

As informações sobre a população residente no Morro do Turano que consta no site Rio+Social ${ }^{8}$ não discrimina a população por raça/cor, o que dificulta especificar o pertencimento racial da população e a verificação de suas discrepâncias raciais, mas de acordo com o IPEA (2011), a distribuição de domicílios urbanos em favelas, segundo sexo e cor/raça do/da e chefia familiar em 2009 no Brasil correspondentes à 2 milhões de domicílios, em torno de 4\%, e

Destes, apenas $33,9 \%$ possuem chefia branca, e por volta de $66 \%$ apresentam chefia negra. Os 
dados mostram ainda que, enquanto $o$ percentual de domicílios em assentamentos subnormais vem diminuindo para os chefes brancos, vem aumentando em especial para aqueles que apresentam chefia de mulheres negras (aumento de 11 pontos percentuais desde 1995). Os dados em geral indicam, portanto, uma significativa melhoria nas condições de habitalidade dos domicílios ao longo dos últimos 15 anos. Entretanto, no que diz respeito aos assentamentos subnormais ${ }^{9}$, a cada vez mais desigual proporção aponta para uma maior e crescente vulnerabilidade nas condições de habitação das famílias chefiadas principalmente por mulheres negras (IPEA, 2011, p. 31).

Esses dados são significativos para pensar as condições de vida das nossas sujeitas e nos leva ao entendimento de que este grupo está submetido a uma maior vulnerabilidade social - e ambiental. De acordo com Tavares (2012), em pesquisa que possibilitou constatar como a divisão interna do trabalho remunerado torna as mulheres mais vulneráveis a viver em condições precárias, dados que, segundo ela, não são nem levantados em diagnósticos sociais para a implementação de projetos de urbanização e moradia. A autora nos fala que as únicas informações desagregadas por sexo, por exemplo, é o quantitativo de mulheres e homens nas áreas de intervenção (TAVARES, 2012, p. $9)$.

Para a autora, outra dimensão na qual podemos refletir sobre a vulnerabilidade das mulheres na cidade diz respeito ao fato de, em um contexto de favela, por fatores econômicos, sobretudo, elas acabam residindo em áreas mais precárias e sujeitas ao risco ambiental, por serem áreas menos valorizadas no mercado imobiliário informal são mais acessíveis a tais famílias. Condições essas, que na nossa avaliação caracteriza o modo como o cotidiano das mulheres se espacializa na favela, seus circuitos, seu modo de apropriação, assim como os limites e obstáculos materiais e simbólicos e que acompanhando os casos de despejos, percebemos que grande parte das famílias já removidas eram chefiadas por mulheres (Idem, p. 16).

Partindo desses pressupostos estabelecidos através do estudo de Tavares passaremos a verificar empiricamente as experiências e estratégias de sobrevivência das mulheres negras moradoras do Bairro Carioca de Triagem após a remoção do Morro do 
Turano, justificadas pelas enchentes que assolaram a cidade do Rio de Janeiro em junho de 2010, onde mais de cem pessoas morreram e milhares ficaram desabrigadas ${ }^{10}$, consideradas as piores chuvas dos últimos $40 \operatorname{anos}^{11}$.

lá era mais fácil. Lá era mais fácil com mais facilidade porque aqui as coisas são muito longe... tipo, mercado fica distante, é mercado, farmácia essas coisas assim fica muito distante tem que andar muito entendeu e lá era muito bem melhor muito mais fácil as coisas entendeu melhorou um pouquinho porque lá era área de risco, mas pra se locomover lá é mais fácil. (Nicole, entrevista realizada em fevereiro de 2016)

Existe ainda a preocupação com o cuidado dos filhos onde, na falta de ter com quem deixar a solução é abrir mão da convivência diária e restringi-la aos finais de semana. No caso de duas das entrevistadas, a solução encontrada foi deixar os filhos sob o cuidado dos pais. A insegurança de ter vizinhos de diversas áreas do Turano não muito íntimos e a distância do ambiente de lazer do condomínio contribuíram para a decisão de Nicole em deixar o filho de 10 anos com o pai, mas o determinante foi o fato de não ter com quem deixa-lo enquanto trabalhava e, apesar de ter sido removida com os pais, não pode contar com esse tipo de ajuda. O mesmo não acontece com Mônica, que mora com o marido e a filha e não teve nenhum parente removido com ela, apenas dois vizinhos. Maria Eduarda, que mora sozinha com as 3 filhas trabalha em casa para poder tomar conta das filhas, ela é manicure.

não tinha ninguém pra olhar porque eu trabalhava, o pai dele [do filho] também trabalhava... e a escola não tinha ninguém pra levar pra escola e não tinha ninguém pra pegar. Igual te falo que é tudo distante, até escola aqui é distante, aí não tinha ninguém pra olhar, eu separei do pai dele [do filho] aqui, aí ele foi embora [o ex-marido]. Conforme ele ficou desempregado e a mãe dele fica em casa (...), aí ela poderia olhar, aí eu deixei ele ficar morando com o pai dele. Porque não tinha ninguém pra poder olhar, pra pegar na escola, entendeu? E eu trabalhava e ele [o marido] e eu também e ele ficava em casa sozinho. Uma criança de dez anos ficava em casa sozinho. Uma criança de dez anos não vai ficar se virando sozinha, por mais que tenha dez anos: 
botar comida, esquentar, esse negócio... aí eu deixei mais por causa disso. (Nicole, entrevista realizada em fevereiro de 2016)

É... fiquei um pouco enrolada, porque eu não tenho com quem deixar meu filho aqui, não posso deixar ele sozinho, ela [a filha mais nova] tem que ir no metrô cheio pra caramba pra ir trabalhar. Eu vou trabalhar no metrô cheio pra caramba com ela, volto cheio... e ele [o filho mais velho], deixo ele lá com o pai dele e ele vem por cá só dia de sextafeira. Mora com o pai dele lá, por causa da escola, não tem com quem deixar ele aqui, não posso deixar ele aí em casa sozinho. Ele tem dez anos... Ele fica lá com ele [o pai] aí sexta-feira ele vem pra cá, segunda ele volta pra escola e ele fica lá com o pai dele. Porque lá o pai dele pode levar ele pra escola, aqui não dá pra levar ele pra escola, fica muito contramão porque eu vou com ela [com a filha menor]. Pra mim eu trabalharia aqui perto... as criança ficasse perto aqui de mim... infelizmente veio esse transtorno. (Mônica, entrevista realizada em fevereiro de 2016)

Minha estrutura toda foi a minha avó. Porque eu moro com ela, então, quer dizer, eu tinha ela e minha única referência era ela. Era ela que olhava meus filhos, era que ficava com eles... quer dizer, minha vó foi tudo na minha vida. Olha! Acho que seria a maioria todas, porque seria a primeira vez que eu iria morar sozinha com as minhas filhas, longe da minha vó da minha mãe. Quer dizer, seria uma experiência muito grande. (Maria Eduarda, entrevista realizada em fevereiro de 2016).

Cinco das oito entrevistadas estão submetidas a inserção precarizada no mercado de trabalho, reflexo da baixa escolaridade $^{12}$, o que corrobora com os dados trazidos por Tavares e que, no caso destas mulheres, terá consequências nas possibilidades ou não de garantir condições de arcar com as despesas do condomínio com consequências na sua possibilidade de permanência.

\section{$O$ custo de vida como uma ameaça à permanência das famílias}

Lícia Valladares já na década de 80, ao analisar o programa de remoções de favelas do Rio de Janeiro empreendido pela CHISAM ${ }^{13}$, nos traz elementos que nos permitirão refletir sobre alguns aspectos desse trabalho. Em sua pesquisa 
a autora verificou que em 1970 finalizavase uma remoção das favelas situadas na orla da Lagoa Rodrigo de Freitas e que na mesma época as favelas da Zona Sul que restavam paradoxalmente continuavam a crescer. Para ela, após algum tempo no conjunto habitacional para onde eram removidas, as pessoas retornavam à favela.

No caso das/os moradores de Triagem, percebemos em suas falas $o$ mesmo desejo, uma delas, Ágata, mostra a complexidade de sua situação ao se dividir entre a felicidade de ter uma casa de alvenaria e as dificuldades que tem para custear a vida no condomínio, sentimento compartilhado por Nicole e Vanessa:

Não, a gente tava doido pra vir morar aqui, mas a gente achou tipo que as contas ia ser reduzida, tipo, luz: eu não tenho nem ar condicionado, eu pago $\mathrm{R} \$ 332$ de luz. Não tenho ar condicionado, eu achei que ia ser uma melhoria. Não é que é que é ruim morar aqui só que tipo eles tiraram a gente de um lugar que a gente não pagava quase nada pra chegar aqui a gente tem que pagar água, luz, condomínio... tudo entendeu? e fica muito pesado, tem gente que não tem condições de pagar entendeu? Eu ainda tenho meu pai, que me ajuda, tenho minha mãe, mas eu trabalho eu que pago minhas contas mas só que foi bom aqui é bom de morar, mas paga muita coisa. (Nicole, entrevista realizada em fevereiro de 2016)

Muita gente não queria vir pra cá. Muita gente, muita gente vendeu isso aqui, mesmo sabendo que não pode vender, muita gente vendeu. Por não ter como sobreviver, entendeu? Não ter como pagar as contas (...). É conta de luz que vem quatrocentos reais, que tu pensa... ou eu pago a conta de luz ou eu faço uma compra, entendeu? É isso! Quatrocentos reais de luz; cem reais que vem de gás, então assim... é praticamente a mesma coisa. (Vanessa, entrevista realizada em fevereiro de 2016)

É. Por esse motivo de não conseguir pagar as contas, e aqui é assim se você não conseguiu... aí botaram uma água pra gente pagar que ainda não é nem registrada pela CEDAE, porque no caso a gente não era nem pra tá pagando nem a água. Aqui você paga uma água e um condomínio que aí você não tem água, tá, a água não cai direito e você é obrigado a pagar, porque se você não pagar eles vem e corta e a água não é legalizada pela CEDAE (...) Você pegar, você sair 
do lugar, pra você se habitar num lugar onde você não conhece, assim, a ambientação direito, pra eles foi muita diferença, até eles pega e se acostumar, no entanto que eu tava acabando de conversar aqui com a minha sobrinha, né, que eu tô querendo vender aqui pra comprar uma casa em outro lugar perto dos meus parentes, tudo, porque eles não gostaram daqui, eles não gostaram daqui. Fala em ir embora eles falam que qué ir (...). Você tem que ter uma pessoa pra te ajudar, porque se você não tiver uma pessoa pra te ajudar você não vai viver aqui, não vai viver aqui! Uma pessoa só é muito difícil, entendeu? Se você falar assim pra mim, Ágata eu vou numa praia, eu não vou porque eu não tenho dinheiro. (Ágata, entrevista realizada em fevereiro de 2016).

Ainda em Valladares (1980), encontramos o que ela chamou de "práticas de distorção" da qual os moradores removidos lançavam mão como uma "resposta adaptativa" à introdução de despesas suplementares muito significativos para o orçamento dos exfavelados (VALLADARES, 1998: 111). Para ela, as práticas de distorção representam uma resposta social à ação governamental em que os favelados reagiram na medida de suas possibilidades (Idem: 113), configurando uma forma de luta pela sobrevivência, luta pela subsistência que, nessas condições, segundo ela, assume um caráter de luta individual, de protesto desorganizado (Ibidem: 125).

A reflexão trazida por Michel de Certeau (1998) é interessante por problematizar as manobras realizadas pelos dominados na busca de uma reorganização cotidiana. Pensar de forma não-dicotômica em termos de organizados/desorganizados pode, nesse sentido, possibilitar mais amplamente a apreensão da complexidade dos dilemas enfrentados por essas mulheres. Ao indagar sobre que "maneiras de fazer" formam a contrapartida, do lado dos consumidores (ou dominados) dos processos mudos que organizam a organização sócio-política, Certeau nos mostra que

Essas "maneiras de fazer" constituem as mil práticas pelas quais os usuários se reapropriam do espaço organizado pelas técnicas da produção sóciocultural. Elas colocam questões análogas e contrárias às abordadas no livro de Foucault: análogas porque se trata de 
distinguir as operações quase microbianas que se proliferam no seio das estruturas tecnocráticas e alteram o seu funcionamento por uma multiplicidade de "táticas" articuladas sobre os "detalhes" do cotidiano; contrárias por não se tratar mais de precisar como a violência da ordem se transforma em tecnologia disciplinar, mas de exumar as formas sub-reptícias que são assumidas pela criatividade dispersa, tática e bricoladora dos grupos ou dos indivíduos presos agora nas redes da "vigilância". Esses modos de proceder e essas astúcias de consumidores compõe, no limite, a rede de uma anti-disciplina (CERTEAU, 1998: 41-42).

Se considerarmos os desafios colocados para as mulheres brasileiras na atual conjuntura econômica e política do país, o impacto da crise econômica para a vida das mulheres do mundo todo, o mercado imobiliário na cidade do Rio de Janeiro e a quantidade de pessoas vendendo (ou com a intenção de) apartamentos no mesmo local, presume-se aqui que esse aspecto trazido pela remoção pode rebaixar ainda mais as condições de vida dessas mulheres.

Além disso, as aspirações de um lugar ideal, imaginado pelas famílias antes de receberem as chaves dos apartamentos expôs a fragilidade das políticas pensadas para as camadas populares: enchentes, tráfico de drogas e incursões policiais violentas fazem parte da rotina desses moradores. Um dado que chamou a atenção foi a atitude quase que unânime em silenciar esses fatos, tivemos pouquíssimos relatos desses detalhes que faria alguma diferença na própria avaliação dos moradores das condições de vida em Triagem e revela que algumas "regras" implícitas na favela também servem para o Bairro Carioca.

Dona Elza (entrevistada em fevereiro de 2016) foi quem pareceu mais insatisfeita com as condições de vida do condomínio e também a única que não me permitiu fazer o registro fonográfico. Em sua fala apareceram elementos imprescindíveis para um exame mais aprofundado das insatisfações que poderiam acometer aquelas pessoas, emblemáticas para uma avaliação do “Legado Olímpico”. 
que lá e aqui é aquele negócio a correria muito grande, entendeu? Você não pode deixar as criança ficar assim brincano ali na rua que daqui a pouco você tem que sair correndo pra sair gritando porque vem os polícia, aí dá tiro mesmo, não tem uma segurança. Eu vou falar pra você, eu me sentia mais tranquila na favela do que aqui. (Ágata, entrevista realizada em fevereiro de 2016)

eu penso que, assim, eu quero uma coisa mais tranquila pro meu filho. Quero que ele tenha... não que ele passe pela mesma coisa que eu passei, porque no morro você vê muita coisa, entendeu? E eu penso que, assim, eu quero um lugar onde ele possa ver o certo e o errado, ele possa conviver com isso, mas que ele tenha oportunidade também de ter coisas boas, entendeu? Não ter só coisa ruim cercando ele... só tráfico, falta de saneamento básico, falta de tudo, entendeu? Eu pretendo dar uma vida melhor pra ele no que eu puder, entendeu? (Vanessa, entrevista realizada em fevereiro de 2016)

O que eu imaginava aqui é o seguinte, um lugar... aqui é bom de morar, mas só que tem umas coisas aí que tá atrapalhando, entendeu? No meu caso, até não atrapalha, porque lá no morro a gente tá acostumado a lidar com certas partes, você deve ter mais ou menos noção do que que, tá ok. (...) e mais outra coisa que agente num que nem fala. Num sei se você percebeu, quando você vinha pra cá, o corre corre ai, polícia tudo... É todo dia isso, todo dia isso. (Pedro, entrevista realizada em fevereiro de 2016)

A solução em condomínio fechado ${ }^{16}$ seria a opção que proporcionaria mais segurança aos moradores, mas de acordo com Andrade (2015), esta solução se mostra inócua e até inadequada, uma vez que para a segurança, o controle social tende a ser mais eficaz do que as barreiras físicas (Andrade, 2015: 25). Quando esses fatores são cruzados com o histórico de violações dos direitos humanos em áreas carentes, temos um agravante para a vida dessas pessoas em local fechado: a impossibilidade de se abrigar em caso de incursão policial.

Curiosamente a maioria das pessoas considera que houve melhora na sua qualidade de vida. Em que pese as ressalvas, identificamos um otimismo que talvez esteja associado ao simples fato de não residirem mais no morro, não mais 
associados ao espaço criminalizado e livres da discriminação espacial no mercado de trabalho. Mesmo que ainda tenham que conviver com alguns dos problemas relacionados à segurança que enfrentavam no Morro, como por exemplo, a atuação arbitrária da polícia em enfrentamento ao do tráfico varejista de drogas. $\mathrm{O}$ fato de todos os entrevistados serem moradores das áreas mais altas e precarizadas do morro pode ter sido um determinante para esta avaliação por parte dos moradores.

Observamos aqui, através dos depoimentos e descrição da trajetória de famílias removidas pelo poder público do Morro do Turano que dependendo do formato da família, as mulheres terão uma atitude diferente frente às possibilidades oferecidas pelo novo local de moradia. As mulheres com menos filhos e/ou que recebiam algum tipo de ajuda seja de maridos ou parentes tentariam garantir sua permanência nesse novo local.

As/os sujeita/os foram unânimes quanto às dificuldades representadas pelo aumento do custo de vida. Todas/os as/os entrevistadas/os demonstraram que isso representava um ônus e que haveria a necessidade da substituição de despesas, mas evidências não conduzem a percepção imediata na necessária piora das condições de vida dos sujeitos investigados - como afirmamos hipoteticamente -, mas sim à pertinência de se considerar a possibilidade real de assumir as despesas com serviços inerentes ao tipo de moradia adotado pelo Morar Carioca, o condomínio. Ainda, alguns relatos trazem a dificuldade de adaptabilidade relacionada à convivência entre os vizinhos, dificultada pela disposição dos blocos, bem próximos uns dos outros e que não configuram espaços de convivência.

Verificamos um ambiente impessoal da relação entre vizinhos, que reflete a sociedade na qual vivemos $\mathrm{e}$ demonstra um declínio do espírito comunitário próprio das relações de vizinhança dependentes dos laços de solidariedade, necessários a sobrevivência dos oprimidos. Não se pretendeu aqui traçar uma análise com olhar homogeneizador sobre as favelas e seus moradores, mas refletir sobre os principais problemas enfrentados contemporaneamente por essa parcela da população que sofre os reflexos do recrudescimento das demandas do capital em uma das cidades mais caras do mundo.

\section{Considerações finais}

O maior nível de vulnerabilidade social a que está submetida a mulher negra entendidos a partir da interseccionalidade de opressões, explica a 
manutenção das desigualdades, manifestadas também na apropriação e produção do espaço urbano que, baseada na racionalidade capitalista, se desenvolveu no Brasil atrelada à hierarquização racial.

No caso das famílias realocadas em áreas centrais, como as famílias removidas do Morro do Turano para o Bairro Carioca de Triagem, os moradores enfrentam vários desafios na luta pela sobrevivência, que vão desde questões relacionadas ao aumento do custo de vida causadas mais diretamente pela cobrança de serviços e, em alguns casos, da necessidade de deslocamento para os antigos locais de trabalho.

Através dos depoimentos das mulheres removidas examinamos que dependendo do formato da família as mulheres se utilizarão de diferentes estratégias para manutenção frente às possibilidades oferecidas pelo novo local de moradia. Notamos que as mulheres com mais possibilidades de adaptação são as que têm menos filhos e/ou que recebiam algum tipo de ajuda.

Um dado significativo foi a dificuldade desencadeada pelo aumento do custo de vida, em grande parte pela falta de tarifas sociais para o pagamento dos serviços inerentes à formalidade da moradia e ao formato de empreendimento adotado pela prefeitura, o condomínio. O ônus representado pelas despesas adicionais relativas à moradia ficou explícito nos depoimentos, assim como a necessária substituição de despesas acarretando uma piora nas condições de sobrevivência das famílias verificadas, mas mesmo assim as/os sujeitas/os relataram uma melhora na qualidade de vida.

Essa sensação de melhora, muito provavelmente, está atrelada à sensação de aquisição de um bem muito valorizado na nossa sociedade, a casa própria, e que em se tratando de um bem legalmente reconhecido - diferente de uma casa adquirida na favela - confere ao seu dono um status de cidadão, mesmo que seus direitos enquanto tal sejam constantemente violados por agentes policiais, pela oferta deficitária de serviços públicos essenciais ou pelas enchentes provocadas pela infraestrutura deficitária do empreendimento, provocado por sua vez, em decorrência da tentativa de rebaixamento dos valores do projeto, característico do Programa Minha Casa, Minha vida.

Para algumas famílias, a venda dos apartamentos foi a solução encontrada para o problema da impossibilidade de arcar com as despesas inerentes à vida no Bairro Carioca de Triagem; solução esta que, dada a grande oferta de apartamentos 
no mesmo local impossibilitaria uma transação compatível à compra de um outro imóvel em uma das cidades mais caras do Brasil. Em média o preço cobrado por apartamento é de cinquenta mil reais, valor módico, tendo em vista os valores de imóveis em um morro pacificado, como é o caso do Morro do Turano.

A expectativa de uma vida melhor no condomínio foi substituída pela batalha cotidiana na busca por melhores condições de vida e demonstra que essas mulheres representam e sobrevivem com diferentes práticas cotidianas, acabando por vencer as dificuldades a partir de ajustes realizados a curto prazo. A procura por soluções para a família remete à possibilidade de, mesmo com algum prejuízo, driblar uma política pública que não foi sensível às reais condições de vida do público atendido, revelando mais uma vez que não se trata especificamente de uma política social, mas de um arranjo espacial na qual a realocação das famílias é um protocolo a ser seguido, não havendo a necessária preocupação com a permanência das pessoas nos apartamentos.

Concluímos que a cidade-mercadoria acaba por se efetivar enquanto inviabilizadora de políticas coerentes ao exercício pleno da cidadania, sendo necessário para tanto, no caso das famílias já removidas, pelo menos a garantia de tarifas compatíveis com a faixa de renda de cada uma. Neste caso, as políticas utilizadas são releituras de políticas excludentes e uma demonstração da utilização de um viés de urbanismo que privilegia a maximização dos lucros em uma nova forma de acumulação, com consequências diretas para as populações mais vulneráveis que, no caso analisado, seriam as mulheres negras chefes de família.

\section{NOTAS}

1 Mestre pelo Programa de Pós-Graduação em Relações Étnico-Raciais do Centro Federal de Educação Celso Suckow da Fonseca - CEFET/RJ, Graduada em História pela Universidade do Estado do Rio de Janeiro (2013) e especialista em Educação e Relações Raciais pela Universidade Federal Fluminense (2015). Minha investigação tem-se centrado principalmente nos temas sobre desigualdades raciais e de gênero, direito à cidade, políticas públicas e educação para as relações raciais.

2 Aderimos a temporalidade defendida por Vainer (2011) e Bienenstein (2011) ao refletirem sobre esse contexto. Para Bienenstein, que avalia as motivações, discursos e impactos que os Jogos Pan-Americanos de 2007 produziram na cidade do Rio de Janeiro, levanta aspectos relativos à construção da "Cidade Olímpica" vinculada às Olimpíadas de 2016 e à Copa de 2014 e assume a perspectiva de que tal iniciativa se trata de um processo que teve início na década de 1990, durante o primeiro governo Cesar Maia (1993- 
1998). Para ele, desde então, um novo padrão de gestão e planejamento urbano foi adotado voltado à implementação de projetos hegemônicos de cidade, preenchendo um vazio de projetos (políticos e econômicos) que o Rio de Janeiro vinha enfrentando. Vainer adota a mesma temporalidade e situa a realização dos Jogos Olímpicos de 2016 no Rio de Janeiro enquanto um desenlace da trajetória ao longo da qual uma nova concepção de cidade e de planejamento urbano se impôs, considerando como momento simbólico desta concepção a elaboração do Plano Estratégico da Cidade levada a cabo em 1993 e 1994.

${ }^{3}$ A remoção foi pensada como a primeira solução para o "problema favela", que se daria na tentativa de erradicá-la. Raquel Rolnik, em prefácio à obra de Faulhaber e Azevedo (2015), nos fala - apoiada nos dados apesentados pelos autores - que, se Pereira Passos a Carlos Lacerda ficaram consagrados na memória coletiva como representantes da política de despejos massivos, o número de pessoas removidas na gestão Eduardo Paes supera, e muito, o das anteriores. Para a autora, esses dados alteram nossa compreensão da história, que ganha maior complexidade com novas mediações entre o público e o privado, com a extração sem precedentes de lucros que combina ganhos imobiliários e financeiros. A remoção total se apresenta como a modalidade mais radical, mas existe também a remoção branca - que deriva do processo de gentrificação - e a remoção parcial. No Morro Turano, por exemplo, está em curso o processo de remoção parcial, podendo ter como motivação desde a urbanização no local (para a abertura e alargamentos de becos e vielas), quanto pelo alegado risco ambiental.

4 O Decreto nº 36388 de 29 de outubro de 2012 oficializa o Programa Municipal de Integração de Assentamentos Precários Informais - Morar Carioca. Disponível http://www.iabrj.org.br/morarcarioca/wpcontent/uploads/2012/11/decreto_36388.29.10.2 012_morar_carioca.pdf

5 Disponível em: http://www.secovirio.com.br/Noticias/Noticias/P rograma-de-Integracao-de-Assentamentos-

Precarios-Informais---Morar-Carioca-

5870.html?tpl=printerview

${ }^{6}$ Criado em 1959, a partir de uma articulação do governo brasileiro (Juscelino Kubitschek) com o governo dos Estados Unidos (Dwight Eisenhower) diante da ameaça do avanço do socialismo, na época da Guerra Fria. O financiamento inicial destinava-se ao crescimento econômico dos países considerados atrasados (propícios à aceitação das ideias comunistas), mediante o combate à pobreza, com base na concepção desenvolvimentista (e regional) (SANTANA, 2006). O banco pertence, hoje, a 48 países membros (26 países mutuários da América Latina e do Caribe e 22 não mutuários). $\mathrm{O}$ poder de voto de cada país membro depende da subscrição de capital ordinário que cada país tenha no banco. A partir dos anos 1970, os bancos multilaterais passam a defender a necessidade dos ajustes estruturais, especialmente da Reforma do Estado, interligando-se ao projeto neoliberal e ao processo de acumulação flexível (SANTANA, 2006). Considera-se que os organismos multilaterais (como o Fundo Monetário Internacional (FMI), o Banco Mundial e o BID) têm atuado na coordenação política e econômica dos interesses das frações de classe dominante e correspondem, segundo Santos (2003), à "inteligência geral" do capital. Nesse sentido, o BID constrói e repassa aos governos nacionais e locais uma série de orientações de políticas econômicas e sociais através de acordos de empréstimo, na forma de modelos de gestão para esses governos (SOARES, 2012: 22). O BID formula para cada país da América Latina e do 
Caribe uma série de estudos e orientações de políticas nos denominados Documentos de País e de Estratégia, onde são definidas as estratégias do banco em vários setores de políticas (Idem: 29).

$$
\text { Disponível }
$$

http://www.rio.rj.gov.br/web/smhc/conheca-oprograma

${ }^{8}$ No caso das não urbanizáveis, diagnosticadas pela Prefeitura como situação de risco ou inadequada ao uso residencial, as famílias estão sendo cadastradas e reassentadas em unidades habitacionais produzidas pelo Programa Minha Casa, Minha Vida.

9 Como não ter impedido o crescimento [das favelas] verificado nos anos 1990, [o que] acabaria permitindo a inclusão da possibilidade da erradicação, algo que o debate do início dos anos 1990 havia afastado, mas que atualmente não seria mais possível entender como sendo uma medida autoritária (MAGALHÃES, 2013: 112).

${ }^{10} \mathrm{http}: / /$ www.riomaissocial.org/territorios/turan o/

11 Utilizado aqui como sinônimo de favela, considerando que o título do capítulo do qual foi extraído o texto é "Habitação e saneamento Distribuição de domicílios urbanos em favelas, segundo sexo e cor/raça do/da chefe".

12 http://blogs.estadao.com.br/olhar-sobre-omundo/drama-no-rio/

13

Disponível

em:

<http://www.gazetadopovo.com.br/vida-ecidadania/pior-chuva-dos-ultimos-40-anos-causaestragos-e-dezenas-de-mortes-no-rio-

11 eq3ja5zxz7gro41r1otom6m $>$. Consultado dia 23/03/2016.

14 Três das nove entrevistadas trabalham como auxiliar de serviços gerais, uma atendente de lanchonete, uma manicure (informal); uma auxiliar de creche, uma auxiliar administrativa e uma aposentada. Dos homens temos um porteiro, um gráfico e um aposentado. Apenas dois dos nove entre entrevistados tem ensino médio (duas mulheres), sendo um completo e um incompleto.

${ }^{15}$ Coordenação de Habitação de Interesse Social da Área Metropolitana do Grande Rio.

${ }^{16}$ Conjunto habitacional cercado, controlado por uma ou mais guaritas.

\section{REFERÊNCIAS BIBLIOGRÁFICAS}

ALBUQUERQUE, Fátima; CORRÊA, Edison; ARAÚJO, Deborah. Habitação em Foco: Informativo da Secretaria Municipal de Habitação, $\mathrm{n}^{\mathrm{o}}$ 43, 2014. Disponível em: <http://www.rio.rj.gov.br/dlstatic/10112/180365 /4114942/News_HABITACAOEMFOCO_43.pdf $>$. Consultado em 13/05/2016.

ANDRADE, Luciana da Silva (Coord.). Para Além da Unidade Habitacional: pela moradia e pela cidade no contexto da construção da [minha] casa e da [minha] vida. UFRJ/PROURB/CiHabE，2015. Disponível em: $<$ http://www.prourb2.fau.ufrj.br/para-alem-daunidade-habitacional-pela-moradia-e-pela-cidadeno-contexto-da-construcao-da-minha-casa-e-daminha-vida/>. Consultado em 20/05/2016.

AZEVEDO, Lena; FAULHABER, Lucas. SMH 2016: remoções no Rio de Janeiro Olímpico. Rio de Janeiro: Mórula, 2015.

CAVALLIERI, Fernando; VIAL, Adriana. Favelas na cidade do Rio de Janeiro: o quadro populacional com base no Censo 2010. Instituto Municipal de Urbanismo Pereira Passos /Prefeitura da Cidade do Rio de Janeiro, 2012. Disponível em: <http://portalgeo.rio.rj.gov.br/estudoscariocas/d ownload\%5C3190_FavelasnacidaFavelasnacidaded _Censo_2010.PDF >. Consultado em 18/0/2016.

CERTEAU, Michel de. Introdução Geral. In: A invenção do cotidiano: artes de fazer. $3^{\text {a }} \mathrm{Ed}$. Petrópolis: Vozes, 1998.

Comitê Popular Rio da Copa e das Olimpíadas. Megaeventos e Violações dos Direitos Humanos no Rio de Janeiro Dossiê do Comitê Popular da Copa e Olimpíadas do Rio de Janeiro. Disponível em: $<$ http://www.apublica.org/wpcontent/uploads/2012/09/dossic3aamegaeventos-e-violac3a7c3b5es-dos-direitos- 
humanos-no-rio-de-janeiro.pdf $>$. Acesso em 03/03/2016.

COMPAS, Rose. Minha Casa, Minha Vida: O Revival do BNH? In: MARAFON, Glaucio José; SANTOS, Angela M. S. Penalva; Sant'Anna, Maria J. Gabriel. Rio de Janeiro: Um território em mutação. Rio de Janeiro: Gramma: FAPERJ, 2012. pp. 11-28.

CREARY, Melissa; WILLIAMS, Erica Lorraine. The Place of Afro-Brazilian Women in the World Cup. 2014. Disponível em: http://www.huffingtonpost.com/melissacreary/the-place-ofafrobrazilia_b_5501037.html >. Consultado em 20/05/2016.

CRENSHAW, Kimberlé. Documento para o encontro de especialistas em aspectos da discriminação racial relativos ao gênero. In: Revista Estudos Feministas, v. 10, n. 1, 2002.

Diário Oficial do Município do Rio de Janeiro. Diretrizes Básicas para a Execução dos Serviços Execução das obras e serviços do Complexo de Triagem. D.O.RIO n ${ }^{\circ}$ 136. Rio de Janeiro, 2010. p. 103. Disponível em: http://doweb.rio.rj.gov.br/ler_pdf.php?edi_id=11 $68 \&$ page $=23>$. Consultado em 20/05/2016.

Dossiê do Comitê Popular da Copa e Olimpíadas. Megaeventos e Violação dos direitos Humanos no Rio de Janeiro, 2013 e 2014. Disponível em: $<$ https://comitepopulario.files.wordpress.com/201 4/O6/dossiecomiterio2014_web.pdf:> $<$ http://comitepopulario.files.wordpress.com/201 3/05/dossie_comitepopularcoparj_2013.pdf>.

Consultado em 05/02/2015.

FERREIRA, Vanessa Nolasco. Unidades De Polícia Pacificadora: Militarização da Pobreza como Resposta à Violência Urbana? Escola Nacional de Saúde Pública Sérgio Arouca (ENSP): Rio de Janeiro: 2013. Disponível em: <http://www.politicaemsaude.com.br/anais/o rais_painel/069.pdf $>$. Consultado em 05/04/2016.

FRANÇA, Danilo; RIOS, Flavia; LIMA, Márcia. Articulando Gênero e Raça: A participação das mulheres negras no mercado de trabalho (19952009). In: MARCONDES, Mariana Mazzini [et al.] (Orgs.). Dossiê Mulheres Negras: retrato das condições de vida das mulheres negras no Brasil. Brasília: Ipea, 2013.

Gonçalves, Rafael Soares. A construção social do risco e as remoções das favelas cariocas. $36^{\circ}$ Encontro Anual da Anpocs - GT 3 - Conflitos ambientais, terra e território: estratégias de resistência e construção de direitos, 2012. Disponível em: <http://www.anpocs.org/portal/index.php?optio $\mathrm{n}=\mathrm{com} \_$docman\&task $=$doc_view\&gid $=7866 \&$ Item $\mathrm{id}=76>$. Consultado em 16/03/2016.

; NETO, Nelson Lima Felix. A noção de risco e o retorno de remoções de Favelas em tempos de grandes eventos na cidade do Rio de Janeiro. In: I Congresso Latinoamericano de Ecología Uurbana. Libro de Trabajos en Extenso Primer Congreso Latinoamericano de Ecología Urbana: desafíos y escenarios de desarrollo para las ciudades Latinoamericanas. Buenos Aires: Gral Sarmiento, 2012a.

GONZALEZ, Lélia. Mulher negra. In: NASCIMENTO, Elisa Larkin. Guerreiras $d a$ natureza: mulher negra, religiosidade e ambiente. São Paulo: Selo Negro, 2014. Coleção Sankofa: Matrizes africanas da cultura brasileira; 3.

A mulher negra na sociedade brasileira: uma abordagem político-econômico. In: LUZ, Madel. O lugar da mulher. Rio de Janeiro: Graal, 1982.

HAESBAERT, Rogério. Identidades Territoriais. In: ARAUJO, F.G.B de; HAESBAERT, R. (Orgs). Identidades e territórios: questões e olhares contemporâneos. Rio de Janeiro: Acess, 2007.

HECK, Charles. Justificativa de "Área de Risco" para Remoção de Favelas: o caso do Santa Marta. Rioonwatch, 2013. Disponível em: http://rioonwatch.org.br/?p=8370

HIRATA, Helena. Gênero, classe e raça: interseccionalidade e consubstancialidade das relações sociais. In: Tempo social - Revista de sociologia da USP, v. 26 - n. 1. pp. 61-73. Disponível em: <http://www.revistas.usp.br/ts/article/view/849 79>. Consultado em 08/05/2014.

HOOCKS, Bell. Intelectuais Negras. In: Estudos Feministas $n^{\circ} 2-$ ano 3, 1995. pp. 464478. Disponível em: <https://periodicos.ufsc.br/index.php/ref/article/ view/16465>. Consultado em 03/05/2016.

A teoria como prática libertadora. In: Ensinando a transgredir: a educação como prática da liberdade. São Paulo: Editora WMF Martins Fontes, 2013. p. 86.

Laerte Costa Silva; Pedro José Farias Fernandes. O Discurso Ambiental e o Controle das Favelas na 
Cidade do Rio de Janeiro. In: Encontro Nacional de Geógrafos. Belo Horizonte. Anais, 2012. Disponivel em: <http://plutao.sid.inpe.br/col/dpi.inpe.br/plutao/ 2012/06.21.19.17.28/doc/O\%20Discurso\%20Amb iental $\% 20 \mathrm{e} \% 200 \% 20$ Controle $\%$ 20das $\% 20$ Favelas $\%$ 20na\%20Cidade\%20do\%20.pdf $>$. Consultado em 25/03/2016.

LEFEBVRE, Henri. O direito à cidade. São Paulo: Centauro, 2001.

MAGAlHÃES, Alexandre. O "legado" dos megaeventos esportivos: a reatualização da remoção de favelas no Rio de Janeiro. Horiz. antropol. [online]. 2013, vol.19, n.40, pp.89-118. ISSN 0104-7183. Disponível em: $<$ http://www.scielo.br/scielo.php? script=sci_artte xt\&pid=So 104-7 1832013000200004 >. Consultado em 08/02/2016.

MARCONDES, Mariana Mazzini [et al.] (Orgs.). Dossiê mulheres negras: retrato das condições de vida das mulheres negras no Brasil. Brasília: Ipea, 2013.

MARTINS, Isis do Mar Marques. Território e Estado: Uma perspectiva de políticas públicas para favelas no Rio de Janeiro a partir da matriz do conceito de "território pacificado". XII Colóquio Internacional de Geocrítica- Lãs independências y construcción de estados nacionales: poder, territorialización y socialización, siglos XIX-XX. 2012. Bogotá, 7 al 11 de Mayo.

MEDEIROS, Bianca Freire; MENEZES, Palloma Valle e VILAROUCA, Márcio Grojó. Gringos no Santa Marta: quem são, o que pensam e como avaliam a experiência turística na favela. In: MARAFON, Glaucio José; SANT'ANNA, Maria Josefina Gabriel e SANTOS, Angela Maria S. Penalva. Rio de Janeiro: um território em mutação. Rio de Janeiro: Gramma: FAPERJ, 2012.

MELO, Hildete Pereira de. Gênero e pobreza no Brasil. Relatório Final do projeto Governabilidad Democratica de Género en America Latina y el Caribe. CEPAL/SPM. Brasília, 2005. Disponível em: <http://portal.mte.gov.br/data/files/FF8080812 BAFFE3Bo12BCBoB9B4B1EBA/GEneroPobreza _Brasilo4.pdf>. Consultado em 18/11/2015.

MENEZES, Juliana. Morar Carioca: Um legado olímpico que anda a passo lento. In: VozeRio, 2015 . Disponível em: <http://vozerio.org.br/Um-legado-olimpicoque-anda-a $>$. Consultado em 10/11/2015.
NUNES, Maria Julieta. Ano 2010: visão panorâmica das políticas governamentais voltadas à favela. GT: Gestão Social, Políticas Públicas e Território. VI Encontro de Pesquisadores em Gestão Social - ENAPEGS. São Paulo, 2012. Disponível em: <http://www.ippur.ufrj.br/download/semana_pu r_2010/completos/Julieta.pdf $>$. Consultado em $05 / 11 / 2015$.

OLIVEIRA, Isabel Cristina Eiras de. Estatuto da Cidade: para compreender... Rio de Janeiro: IBAM/DUMA, 2001.

PEREGRINO, Ana Izabel de Carvalho. As mulheres e o cotidiano urbano no Brasil. In: $\mathbf{O}$ progresso das mulheres no Brasil. Unifem Brasília, 2006. Disponível em: http://www.mpsp.mp.br/portal/page/portal/Cart ilhas/Progresso\%20das\%20Mulheres\%20no\%20Br asil.pdf $>$. Consultado em 14/12/2015.

PEREIRA, Álvaro Luís dos Santos. A gentrificação e a hipótese do diferencial de renda: limites explicativos e diálogos possíveis. In: Cadernos Metrópole - Observatório das Metrópoles - n. 1 - Dossiê: desenvolvimento desigual e gentrificação da cidade contemporâneaSão Paulo: EDUC, 1999. pp. 307328.

RATTS, Alecsandro J.P. Gênero, Raça e Espaço: Tragetórias de mulheres negras. XXVII Encontro Anual da ANPOCS, 2013. Disponível em:

<http://portal.anpocs.org/portal/index.php?optio $\mathrm{n}=\mathrm{com} \_$docman\&task $=$doc_view\&gid $=4259 \&$ Item $\mathrm{id}=316>$. Consultado em 07/09/2015.

; Souza, Lorena Francisco. Raça e gênero sob uma perspectiva geográfica: espaço e representação. In: Boletim Goiano de Geografia. Instituto de Estudos Sócio-Ambientais. V. 28, n 1, 2008. Disponível em: <http://revistas.ufg.br/index.php/bgg/article/vie w/4907>. Consultado em 18/11/2015.

RIBEIRO, Matilde. Mulheres Negras: uma trajetória de criatividade, determinação e organização. Rev. Estudos Femininos. vol.16, n.3, pp. 987-1004. 2008.

RIBEIRO, Rodrigo Lopes Cavalcanti. Rumo a Triagem: Dilemas do conjunto habitacional Bairro Carioca no atual processo de reassentamento de moradores de favelas do Rio de Janeiro. In: Seminário Nacional sobre Urbanização de Favelas - IURBFAVELAS. São Paulo, 2014. Disponível 
<http://www.sisgeenco.com.br/sistema/urbfavela s/anais/ARQUIVOS/GT3-121-109-

20140630234754.pdf>. Consultado em $18 / 10 / 2015$.

ROCHA, Leandro Pereira da; PESSOA, Marcelo Pessoa. Discriminação Espacial no Mercado de Trabalho: O caso das favelas do Rio de Janeiro. In: Revista Brasileira de Estudos Regionais e Urbanos (RBERU). Vol. 07, n. 1, pp. 38-57, 2013. Disponível em: <http://www.revistaaber.org.br/rberu/article/vie w/86/112>. Consultado em 20/08/2015.

ROLNIK, Raquel (Coord.). Como fazer valer o direito das mulheres à moradia? Relatoria Especial para o Direito à Moradia Adequada. Conselho de Direitos Humanos da Onu. Fourdfoudatrion, 2012 . Disponível em: $<$ http://direitoamoradia.org/wpcontent/uploads/2012/01/guia-mulheresPT.pdf $>$. Consultado em 15/11/2015.

10 anos do Estatuto da Cidade: das lutas pela Reforma Urbana às Cidades da Copa do Mundo [online]. Disponível em: https://raquelrolnik.files.wordpress.com/2013/07 / 10-anos-do-estatuto-da-cidade.pdf $>$. Consultado em 15/11/2015

\section{Territórios Negros nas Cidades Brasileiras: etnicidade e cidade em São Paulo e Rio de Janeiro. Disponível em: $<$ https://raquelrolnik.files.wordpress.com/2013/o 4/territc3b3rios-negros.pdf $>$. Consultado em $15 / 11 / 2015$}

SÁNCHEZ, Fernanda. Cidades reinventadas para um mercado mundial: estratégias transescalares nas políticas urbanas. Anais do IX ENANPUR, Rio de Janeiro, ANPUR/IPUUR/UFRJ, 2001. Disponível em: <http://unuhospedagem.com.br/revista/rbeur/in dex.php/anais/article/view/2157/2110>.

Consultado em 12/10/2015.

SANTANA, Joana Valente. Desenho ideológico do BID: modelo de gestão no Promaben em Belém, Pará. Rev. katálysis, vol.15, n.1, 2012. pp.21-31. Disponível em: <http://www.scielo.br/scielo.php?script=sci_artte $\mathrm{xt \& pid}=\mathrm{S} 1414-49802012000100002$. Consultado em 15/11/2015.

SANTOS, Milton. O Espaço do Cidadão. 7. Ed. São Paulo: Editora da Universidade de São Paulo, 2007.
SILVA, José Carlos Gomes da. História de vida, produção literária e trajetórias urbanas da escritora negra Carolina Maria de Jesus. Texto de estágio de pós-doutoramento. Universidade de Campinas, 2006-7. Disponível em: <http://proex.unifesp.br/santoamaro/docs/cultur a_afro_brasileira/carolina_maria_de_jesus_biograf ia.pdf. Consultado em 15/11/2015.

SILVA, Maria Lais Pereira. "A Batalha do Rio de Janeiro: combatentes e combatidos nas favelas cariocas, 1947-1948”. In: Anais do 6ºminário de História da Cidade e do Urbanismo - 5 séculos de cidade no Brasil. Natal: PPGAU/UFRN, 2000.

SORJ, Bernardo; GUEDES, Luís Eduardo. Internet na f@vela: quantos, quem, onde, para quê. Rio de Janeiro: Centro Edelstein de Pesquisa Social, 2008.

SOUZA, José Nilton de. A Exclusão Pela Urbanização: Favela - Governo e Conflito na Cidade do Rio de Janeiro. In: GEOgraphia - Ano V - No 10, 2003.

TADDEI, Anna; SANTIAGO, Maria Cristina Paiva. Cidadania, Sociedade e Consumo: uma proposta para reflexão. [online]. Disponível em: <http://www.publicadireito.com.br/artigos/?cod $=2 \mathrm{bbc} 1 \mathrm{cc} 8 \mathrm{fd}$ oe 5 f9ex'. Consultado em 03/12/2015

TASCHNER, Gisela. Cultura do consumo, cidadania e movimentos sociais. In: Ciências Sociais - Unisinos. v. 46, n. 1 (online). São Leopoldo, 2010. Disponível em: $<$ http://revistas.unisinos.br/index.php/ciencias_s ociais/article/view/170. Consultado em $02 / 12 / 2015$.

TAVARES, Rossana Brandão. Uma análise das desigualdades de gênero em favelas do Rio de Janeiro: Perspectivas de reconhecimento para o urbanismo. In: Cadernos de Pós-Graduação em Arquitetura e Urbanismo. Vol.12 - $\mathrm{n}^{\mathrm{o}}$ 2, 2012. Disponível em: <http://www.mackenzie.br/dhtm/seer/index.php /cpgau/article/view/tavares.2012.2. Consultado em 07/05/2014.

VAINER, Carlos. Cidade de Exceção: reflexões a partir do Rio de Janeiro. Anais: Encontro Nacional da ANPUR, v. 14. Rio de Janeiro, 2011. Disponível em: $<$ http://unuhospedagem.com.br/revista/rbeur/in dex.php/anais/article/view/2874. Consultado em $15 / 11 / 2015$. 
VELLOSO, João Paulo dos Reis; PASTUK, Marília (Coord.). Turano. In: Favela é Cidade: Plano de Desenvolvimento de Favelas para a sua Inclusão Socioeconônica - Cidade de Deus / Salgueiro / Turano / Formiga. Fórum Nacional: Rio de Janeiro, 2014.

WERNECK, Jurema. Nossos passos vêm de longe! Movimentos de mulheres negras e estratégias políticas contra o sexismo e o racismo. In: Revista da ABPN. v. 1, n. 1, 2010. Disponível em: <http://www.abpn.org.br/Revista/index.php/edi coes/article/view/20/10. Consultado em 05/05/2014.

YIN, Robert K. Estudo de caso: planejamento e métodos. 2. ed. Porto Alegre: Bookman, 2001.

\section{BLACK WOMEN, REMOVAL AND DISCURSIVE ALIGNMENTS: LIFE IN BAIRRO CARIOCA DE TRIAGEM}

ABSTRACT: THIS ARTICLE IS PART OF A BROADER INVESTIGATION THAT PARTS FROM THE QUESTION ABOUT THE EFFECTS OF THE TRANSFORMATIONS OCCURRED IN THE CITY OF RIO DE JANEIRO FACED BY HOUSEHOLDS HEADED BY BLACK WOMEN RESIDENTS IN THE BAIRRO CARIOCA OF TRIAGEM, IN CONSEQUENCE OF ITS REMOVAL FROM THE MORRO DO tURANO, SEEKING TO CharaCterIZE theIR FACING STRATEGIES DURING thIS PROCESS. FROM THE THOUGHT that REMOVALS CONTRIBUTE TO THE PRECARIOUS LIVING CONDITIONS OF SLUM FAMILIES, WITH GREATER DAMAGE TO FAMILIES HEADED BY BLACK WOMEN, HAVING AS PARAMETER ITS HISTORICAL DISADVANTAGE PROVIDED BY THE INTERSECTIONALITY OF RACE OPPRESSION, GENDER AND CLASS, WHICH MAKES BLACK WOMEN HISTORICALLY DISADVANTAGED IN THE SEARCH FOR EFFECTIVE CITIZENSHIP. THUS, WE VERIFY FROM THE LINES OF THE SUBJECTS HOW THEY ARE ORGANIZED TO FACE THIS REALITY, IN ORDER TO OBSERVE HOW SOCIAL PRACTICES ARE EVIDENT IN THE SPEECHES.

KEYWORDS: BLACK WOMEN, REMOVAL, CITIZENSHIP BY CONSUMPTION, BAIRRO CARIOCA DE TRIAGEM. 


\section{LAS MUJERES NEGRAS, LA ELIMINACIÓN Y ALINEACIONES DISCURSIVAS: LA VIDA EN EL}

\section{BAIRRO CARIOCA DE TRIAGEM}

RESUMEN:

este artículo es parte de UNA Investigación más ampla QUe las preguntas sobre los efectos de las

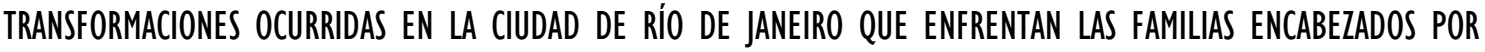
LAS MUJERES NEGRAS MORADORAS DEL baRRIO CaRIOCA COMO CONSECUENCIA DE SU RETIRAdA DEL MORRO DO

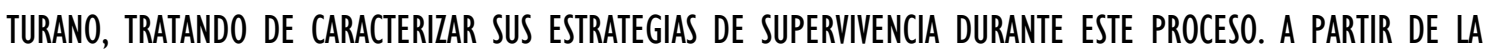

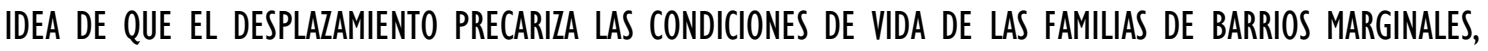

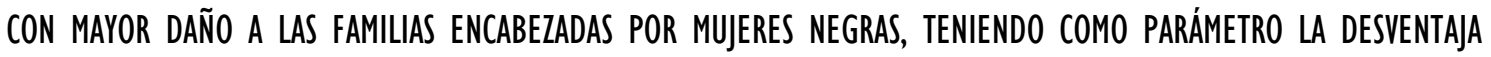

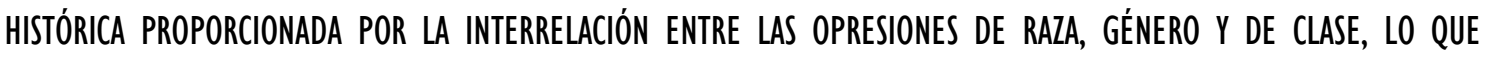
PONE LAS MUJERES NEGRAS hISTÓRICAMENTE EN DESVENTAJA EN LA BÚSQUEDA DE UNA CIUDAdanía EFECTIVA. POR LO tanto, en las vozes de las/los sujetas/tos, vemos como éstos Se organizan para enfrentar dicha

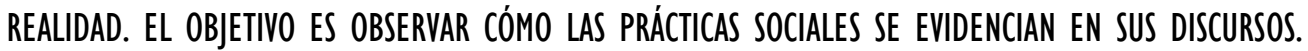

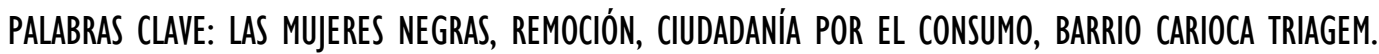

